\title{
TOBACCO USE AND BODY MASS INDEX AMONG ADULT POPULATION IN SELECTED URBAN AREA OF AGARTALA CITY- A CROSS-SECTIONAL STUDY
}

\author{
Shyamal Roy'1, Taranga Reang², Aman Kumar ${ }^{3}$
}

${ }^{1}$ Associate Professor, Department of Medicine, Agartala Govt. Medical College and GB Pant Hospital, Agartala, Tripura.

${ }^{2}$ Assistant Professor, Department of Community Medicine, Agartala Govt. Medical College and GB Pant Hospital, Agartala, Tripura

${ }^{3}$ Final Year PGT, Department of Community Medicine, Agartala Govt. Medical College and GB Pant Hospital, Agartala, Tripura.

ABSTRACT
BACKGROUND
Smoking is responsible for large number of premature deaths in India. Smokeless tobacco is also addictive and associated with
development of risk of cancer of head and neck, oesophagus, stomach and pancreas besides many oral diseases. The objective of
this study is to assess the pattern of tobacco use and association of tobacco use with BMI in adult population.

\section{MATERIALS AND METHODS}

A cross-sectional study was conducted among 150 adult population. Multistage random sampling technique was used for individual selection and data was collected using structured interview schedule.

\section{RESULTS}

Nearly eighty seven percent (86.7\%) knew that tobacco use can cause cancer. It was found that $30.0 \%$ smokes only and $66.0 \%$ used smokeless form of tobacco. Among non-smokers, 3.3\% used khaini, $12.0 \%$ used zarda, 8.0\% used tobacco with betel leaf and $50.0 \%$ used tobacco in multiple forms. It was found that smokers had higher proportion of lower BMI (62.5\%) compared to smokeless tobacco users (37.5\%), but proportion of normal weight was higher among smokeless tobacco users (73.3\%) compared to smokers $(\mathrm{p}=0.007)$.

\section{CONCLUSION}

Smokeless form of tobacco use was quite high in spite of having good knowledge and awareness. We recommend further study involving more subjects including rural and urban population.

\section{KEYWORDS}

Tobacco, Adult Population, BMI, Pattern of Tobacco Use.

HOW TO CITE THIS ARTICLE: Roy S, Reang T, Kumar A. Tobacco use and body mass index among adult population in selected urban area of Agartala city- a cross-sectional study. J. Evolution Med. Dent. Sci. 2018;7(04):510-514, DOI: $10.14260 /$ jemds/2018/114

\section{BACKGROUND}

In India, Tobacco is used in different forms. Use of tobacco in the form of smoking and chewing are quite common in the North Eastern states of India. Tobacco is also used along with Pan (mixture of lime, pieces of areca nuts, tobacco and spices wrapped in betel leaf), Gutka or Pan masala (scented tobacco mixed with lime and areca nuts in powdered form), Khaini and Zarda. India has one of the highest tobacco users in the world characterised by both smoking and smokeless form.(1) In $52^{\text {nd }}$ round of NSSO on morbidity and private health expenditure, it was reported that $51.3 \%$ males and $10.3 \%$ females use tobacco.(2) In NHSDDAA (National Household Survey of Drug and Alcohol Abuse) study in India found that the overall tobacco use among 12 - 60 years found to be $55.8 \%$.(3) According to NFHS IV (2015 - 16) in Tripura, the use of tobacco in any form by women and men are $42.2 \%$ and $67.8 \%$ respectively.

'Financial or Other Competing Interest': None.

Submission 07-12-2017, Peer Review 09-01-2018,

Acceptance 15-01-2018, Published 22-01-2018.

Corresponding Author:

Dr. Taranga Reang,

Assistant Professor,

Department of Community Medicine,

Agartala Govt. Medical College and GB Pant Hospital,

Agartala, Tripura.

E-mail: tarangareang@gmail.com

DOI: $10.14260 /$ jemds $/ 2018 / 114$
In Tripura, $18.8 \%$ and $10.7 \%$ women and men respectively tobacco users tried to stop use of tobacco in any form during past 12 months.(4) In India, 6.4\% women and $44.8 \%$ men use tobacco in any form. In India $29.3 \%$ and $30.6 \%$ women and men respectively tried to stop the use of tobacco of any form during past 24 months.(5) High prevalence of tobacco use was also found among school going adolescent aged 13 - 15 years.(6) The high use of tobacco was associated with high burden of mortality. According to WHO report, almost 6 million death occurs every year due to tobacco which may reach to 8 million by 2030.(7) Smoking is responsible for large number of premature deaths in India. The majority of smoking related premature death occurs in the productive age group of 15 - 59 years.(8) Smokeless tobacco is also addictive and associated with development of risk of cancer of head and neck, oesophagus, stomach, pancreas besides many oral diseases.(7) There are policies, programs and acts for controlling tobacco use in India. In gazette notification dated 29th September 2008 by the Ministry of Health and Family Welfare, Govt. of India that some rules have been amended on tobacco and tobacco products. There must be a statutory warning in the package of the product (Sec 34 of 2003, Prohibition of Advertisement, regulation of trade and commerce, production, supply and distribution) (Amended in packaging and labelling rules 3, 2008).(9) The Global Adult Tobacco Survey (GATS) in India survey collected information on tobacco use in the country among population of aged 15 years and above. 
This study was the large scale survey after the enactment of Cigarette and Other Tobacco Product Act (COTPA, 2003) and launched the National Tobacco Control programme (2007 - 08) in India).(10) Body habitus as described by BMI is related to skeletal size, muscle mass and adiposity. It is also influenced by diet, lifestyle and other environmental factors. The association between low BMI and smoking was reported in many studies.(11,12) Of course, few studies showed that this relationship may be influenced by educational level, gender, ethnicity and frequency of smoking (number of cigarette stick/day). For instance, in Finland the inverse association weakened between smoking and BMI during 1982 - 87, but later it became positive.(13) Educational attainment is known to influence the relation between smoking and BMI in North European population. In this population, smoking is inversely related to BMI at lower level of education and positively associated with higher level of education. $(14,15)$ The objective of this study was to assess the pattern of tobacco use and association of tobacco use with BMI in adult population. The Tobacco Control Programme is in force in the country, even though many people are not aware of the harmful effect of tobacco use.

\section{MATERIALS AND METHODS}

A cross-sectional study was conducted among 150 adult study subjects in a selected urban area of Agartala city during May to June 2017. Sample size was calculated using the formula for single proportion $\mathrm{Z} 1-\alpha / 2^{2} \mathrm{p}(1-\mathrm{p}) / \mathrm{L}^{2}$, where ' $\mathrm{p}$ ' is $40 \%(10)$ and $20 \%$ margin of error with $95 \%$ confidence interval at $5 \%$ level of significance. Person using any form of tobacco for last 12 months or more (current tobacco user) were included. Bhati Abhoy Nagar under Sadar subdivision (Agartala) was selected using multistage random sampling technique. In Bhati Abhoy Nagar, further two mahallas or locality were randomly selected which comprises of about 2000 families and approximately 16,000 populations. One hundred and fifty (150) families were randomly selected from these 2000 families for our present study (lottery method). In each of the families, we have randomly selected one eligible member for our study. A house to house visit was made to find out persons $\geq 18$ years. Participants were interviewed and recorded the information in the interview schedule. Data were collected from one eligible individual in each house through house to house visit using structured interview schedule, height and weight machine. The questionnaire has four sections viz. sociodemographic, knowledge, smoking habits and weight and height measurement. A predesigned, pretested structured interview schedule was used for data collection which narrates about the habits of tobacco use and the pattern of frequency of use of tobacco. Besides the oral questionnaire method, the subjects were assessed for height and weight to calculate BMI. Height was measured to the nearest $1 \mathrm{~mm}$ using a portable stadiometer $(210 \mathrm{~cm} / 84$ inches) (Standard Steel, Ram Bagh Road, Ambala, Haryana, India) with the subject standing straight with the head held in the Frankfurt plane. The subject was requested to stand bare feet over the plate of the stadiometer touching his heel to the stadiometer stand. The horizontal pointer provided over the stand of stadiometer is manually moved around till touching the scalp to measure the height of the subject. The subject's weight without shoes and while wearing light clothes was measured to the nearest $100 \mathrm{gm}$, using a digital weighing scale (Model No. APD 807, Naap 0, Avon Corporation Ltd., 201 - 208, 2nd floor, Raghu Banshi complex, Bharak Mora, Vapi-Silvasa road, Chanod, Gujarat, India). The scale was kept on a flat surface and the subject was requested to step on it in bare feet without holding on to anything. Height and weight measurements were taken twice and the mean of the two measurements was used to calculate the BMI, which was defined as the ratio of body weight $(\mathrm{kg})$ to body height (metres) squared $\left(\mathrm{kg} / \mathrm{m}^{2}\right)$. The BMI has been categorised into underweight $(<18.5)$, normal (18.5 - 24.99) and overweight (25 - 20.99) and obese ( $\geq 30.0$ ). Every day, before going to field, the weighing scale and stadiometer were calibrated with standard weight and height, respectively. The persons who were involved in the measurement of height and weight were entrusted to do the same work throughout the process. In this way, we tried to minimise the interobserver variation. The other persons were made responsible for interviewing participants and recording the information. Individual data collections were kept anonymous and strict confidentiality was maintained. To control bias, WHO KISH table method was applied while selecting the study participants.

\section{Data Analysis}

Data were analysed using SPSS 15.0 version. The subjects were classified according to habits like tobacco smokers and chewers. Further, it was classified according to the form of tobacco use viz. smoking, smoking and chewing and only chewing, number of sticks smoked per day, number of times chewing tobacco in any form per day and so on. For analysis of educational background, the subjects were classified as illiterate, primary, matriculate, higher secondary and graduate and above. The descriptive statistics viz. percentage, mean and standard deviation were calculated. The inferential statistics like Chi-square test was performed to find out the association between dependent and independent variables. The BMI was considered as outcome/dependable variable. The smoking, chewing, age, sex, occupation etc. were considered as independent variables. The dependent variable BMI was made dichotomous by using cut-off points: 18.5 and $25.0 \mathrm{~kg} / \mathrm{m}^{2}$. These were the conventional cut-off points indicating thinness and overweight respectively. For dose response calculation, the number of times per day tobacco used in the form of stick smoked and chewed in the form of pan masala etc. was referred as frequency of habit per day. The number of cigarette stick was classified as 1 to $5 ; 6$ to 10 and $\geq 11$ per day etc. were analysed. The p-value $<0.05$ was considered significant.

The informed consent was obtained from the participants before conducting the study. The ethical approval was obtained from the Institutional Ethics Committee before conducting the study.

\section{RESULTS}

The selected area is densely populated and environmental sanitations are poor. Majority among the respondents were 
within the age group of 21 - 40 years. The overall mean (SD) age of the participants were $42.47( \pm 14.391)$ years.

The mean (SD) age of male and female were 46.15 $( \pm 15.613)$ years and $39.65( \pm 12.771)$ years respectively. Please provide mean age and the standard deviation values. The proportion of male and female were $43.3 \%$ and $56.7 \%$, respectively. Nearly sixty three percent $(62.7 \%)$ read up to primary level. (Table 1) It was found that nearly eighty seven percent $(86.7 \%)$ of the respondents told that cancer might be caused due to prolonged use of tobacco. (Table 2) Thirty one percent of $(31 \%)$ the respondents said that tobacco may cause vision disturbance, $16 \%$ said burning sensation of eyes, $11 \%$ said all of the above (burning eyes, disturbed vision, tearing eyes, itching, blindness) and 38\% did not know anything of its effect on eye. Seventy two percent (72.0\%) heard of COTPA act and $20.7 \%$ knew about punishment. Almost sixty seven percent $(67.4 \%)$ said that as per COTPA act, smoking is prohibited in public places. $15.3 \%$ did not want to ban tobacco and as a reason they said that 'tobacco users cannot live without this (8.0\%),' 'it is addictive, so not possible to quit (7.3\%),' 'production company loss $(0.7 \%)$,' and 'work loss by factory worker $(0.7 \%)$.' We found that $30.0 \%$ smokes only, $66.0 \%$ used smokeless form of tobacco and $4.0 \%$ used both smoking and smokeless form of tobacco. Among smokers $12.7 \%$ smoked cigarette and $16.7 \%$ smoked Bidi. Among non-smokers 3.3\% used khaini, $12.0 \%$ used zarda, 8.0\% used tobacco with betel leaf and 50.0\% used tobacco in multiple forms. Majority among the males (97.8\%) were smokers and females were tobacco chewers $(84.8 \%)$ $(\mathrm{p}<0.001)$. Four percent $(4.0 \%)$ among males were both smokers and tobacco chewers. More than seventeen percent (17.3\%) smokers smoked $\geq 11$ sticks per day (Cigarette/Bidi) and $1.3 \%$ pipe smokers (Hukkah) smoked $\geq 5$ time a day. Twenty percent $(20.0 \%)$ chewed tobacco $\geq 10$ times a day in different forms. The mean $( \pm S D)$ height and weight among males and females were 160.45 (6.769), 149.09 (5.735) and 56.50 (12.546), 52.10 (10.775) respectively. The overall mean $( \pm \mathrm{SD})$ height and weight among respondents were 154.02 (8.374) and 54.02 (11.742) respectively. More than fifty seven percent $(57.3 \%)$ were within normal BMI, overweight $19.3 \%$, undernourished $16.0 \%$ and $7.3 \%$ obese. Smokers had higher proportion of lower BMI (62.5\%) compared to smokeless tobacco users $(\mathrm{p}=0.007)$ (Table 3).

\begin{tabular}{|c|c|c|}
\hline Age Group (yrs.) & Number (N) & Frequency (\%) \\
\hline $20-30$ & 35 & 23.3 \\
\hline $31-40$ & 39 & 26.0 \\
\hline $41-50$ & 36 & 24.0 \\
\hline $51-60$ & 40 & 16.7 \\
\hline$>60$ & 15 & 10.0 \\
\hline \multicolumn{3}{|c|}{ Sex } \\
\hline Male & 65 & 43.3 \\
\hline Female & 85 & 56.7 \\
\hline Married & 148 & 98.7 \\
\hline Unmarried & 2 & 1.3 \\
\hline \multicolumn{3}{|c|}{ Income (Monthly) (Rs.) } \\
\hline -5000/- & 16 & 10.7 \\
\hline $5001-5999 /-$ & 39 & 26.0 \\
\hline
\end{tabular}

\begin{tabular}{|c|c|c|}
\hline $6,000-10,000 /-$ & 85 & 56.67 \\
\hline$>10,000 /-$ & 10 & 6.7 \\
\hline \multicolumn{3}{|c|}{ Religion } \\
\hline Hindu & 81 & 54.0 \\
\hline Muslim & 69 & 46.0 \\
\hline Occupation & 13 & 8.7 \\
\hline Govt. Employee & 137 & 91.4 \\
\hline Unemployed & 5 & 3.3 \\
\hline Diet & 145 & 96.7 \\
\hline Vegetarian & 28 & 18.7 \\
\hline Non-Vegetarian & 94 & 62.7 \\
\hline \multicolumn{2}{|c|}{ Education } \\
\hline Illiterate & 28 & 18.7 \\
\hline Primary & Table 1. Socio-Demographic Profile \\
\hline \multicolumn{2}{|c|}{} \\
\hline
\end{tabular}

\begin{tabular}{|c|c|c|}
\hline Tobacco can Cause Cancer & $\begin{array}{c}\text { Number } \\
\text { (N) }\end{array}$ & $\begin{array}{c}\text { Frequency } \\
\text { (\%) }\end{array}$ \\
\hline Yes & 130 & 86.7 \\
\hline No & 20 & 13.3 \\
\hline \multicolumn{2}{|c|}{ If Yes, which Type of Cancer } \\
\hline Lung & 9 & 6.0 \\
\hline Mouth cavity & 28 & 18.7 \\
\hline Food canal (Oesophagus) & 5 & 3.3 \\
\hline Lung, mouth cavity and oesophagus & 56 & 37.4 \\
\hline Do not know & 50 & 34.7 \\
\hline Filter Cigarette is & \\
\hline Harmless & 10 & 6.7 \\
\hline Harmful & 105 & 70.0 \\
\hline Do not know & 35 & 23.3 \\
\hline
\end{tabular}

\begin{tabular}{|c|c|c|}
\hline \multicolumn{3}{|c|}{$\begin{array}{c}\text { Smoking Tobacco can cause Cough and other Lung } \\
\text { Diseases }\end{array}$} \\
\hline Respiratory difficulties & 100 & 66.7 \\
\hline Allergy & 6 & 4.0 \\
\hline Respiratory difficulties and allergy & 4 & 2.6 \\
\hline Do not know & 40 & 26.6 \\
\hline
\end{tabular}

Smoking and Chewing Tobacco can cause Loss of Appetite

\begin{tabular}{|c|c|c|}
\hline Yes & 120 & 80.0 \\
\hline No & 30 & 20.0 \\
\hline \multicolumn{3}{|c|}{ Tobacco use can cause Failure to Gain Weight? } \\
\hline Yes & 113 & 75.3 \\
\hline No & 37 & 24.7 \\
\hline
\end{tabular}

Tobacco use by Pregnant Mother can cause Small Baby

\begin{tabular}{|c|c|c|}
\hline Yes & 124 & 82.7 \\
\hline No & 26 & 17.3 \\
\hline
\end{tabular}

Tobacco causes Growth Failure to New-Born Baby

\begin{tabular}{|c|c|c|}
\hline Yes & 116 & 77.3 \\
\hline No & 34 & 22.7 \\
\hline \multicolumn{2}{|c|}{ Table 2. Knowledge of the Respondents } \\
regarding Tobacco \\
\hline
\end{tabular}




\begin{tabular}{|c|c|c|c|c|c|}
\hline Variables & \multicolumn{4}{|c|}{ BMI Group } & \multirow{2}{*}{$P$ value } \\
\hline Literacy Status & (\%) Underweight & Normal (\%) & Overweight (\%) & Obesity (\%) & \\
\hline Literate & $18(75.0)$ & $71(82.6)$ & $22(75.9)$ & 11(100.0) & \multirow{2}{*}{0.282} \\
\hline Illiterate & $6(25.0)$ & $15(17.4)$ & $7(24.1)$ & $0(0.0 \%)$ & \\
\hline \multicolumn{6}{|c|}{ Diet } \\
\hline Vegetarian & $0(0.0)$ & $4(4.7)$ & $0(0.0)$ & $1(9.1)$ & \multirow{2}{*}{0.331} \\
\hline Non-Vegetarian & $24(100.0)$ & $82(95.3)$ & $29(100.0)$ & $10(90.9)$ & \\
\hline \multicolumn{6}{|c|}{ Sex } \\
\hline Male & $16(66.7)$ & $34(39.5)$ & $11(37.9)$ & $4(36.4)$ & \multirow{2}{*}{0.094} \\
\hline Female & $8(33.3)$ & $52(60.5)$ & $18(62.1)$ & $7(63.6)$ & \\
\hline \multicolumn{6}{|c|}{ Tobacco Use } \\
\hline Smoking & $15(62.5)$ & $23(26.7)$ & $11(37.9)$ & 2(18.2) & \multirow{2}{*}{0.007} \\
\hline Smokeless & $9(37.5)$ & $63(73.3)$ & $18(62.1)$ & $9(81.8)$ & \\
\hline \multicolumn{6}{|c|}{ Table 3. The Association of Literacy, Diet, Sex and Tobacco Use with BMI } \\
\hline
\end{tabular}

\section{DISCUSSION}

A cross-sectional study was conducted to know the pattern of tobacco use among the adult population of Agartala city during May and June 2017 in West district of Tripura and also to determine the relationship between the use of tobacco and BMI in the study population.

We tried to find out the tobacco use and their body weight. Accordingly, we calculated BMI to know the relationship between tobacco use and their nutritional grade. At the same time we also tried to create awareness among the tobacco users, while doing interviews through asking different health related questions designed in the interview schedule. We had interaction of views regarding tobacco use with the respondents during our data collection. Amongst the study population, majority were females who were in their 30 - 40 years old and housewives and attended up to primary school. Their tobacco awareness was good, and they had appropriate knowledge on tobacco use and its harmful effects.

In the present study, we found that males prefer tobacco in smoking form compared to female. While in case of females, they preferred chewing in the form of pan with betel leaf. A study from India showed that maximum smoking prevalence was found in Meghalaya and minimum in Goa. Mizoram(10) had highest prevalence of smoking by females, where in our study smokeless form was preferred by majority of the females. In case of chewing, Bihar was the highest prevalence(10) of smokeless tobacco. Among females Mizoram had the highest prevalence of smoking and smokeless tobacco use, while Arunachal Pradesh had the highest prevalence of dual use of tobacco. The northeastern states of India had higher prevalence of every form of tobacco use than the other states.(10) Another Indian study(16) showed that all forms of tobacco use were associated with low BMI. The prevalence of low BMI was highest in bidi smokers.(16) In the present study we found that the smokers had comparatively higher proportion of low BMI than smokeless tobacco users, but proportion of normal weight was higher among smokeless tobacco users compared to smokers $(p=0.007)$. A national cohort study(17) showed that mean weight gain attributable to the cessation of smoking. Major weight gain (greater than $13 \mathrm{~kg}$ ) occurred in $9.8 \%$ of the men and $13.4 \%$ of the women who quit smoking.

A study was conducted in Northern Sweden to explore the effect of tobacco use (smoking and smokeless tobacco) and cessation on body weight. Snuff users had slightly higher prevalence of overweight at entry $(\mathrm{PR}=1.20, \mathrm{CI}=1.01-1.42)$. Cessation of tobacco, either cigarettes or snubs, leads to significantly increased weight gain.(18) In the present study, we found that majority of the tobacco chewers were either normal or overweight and obese. A study from North-East India (2003)(19) showed that in the North-East schools boys and girls ever tobacco users ranged from 75.3\% (Mizoram) to $40.1 \%$ (Assam). Mizoram reported the highest current smoking (34.5\%, mainly cigarette) and Assam reported the lowest (19.7\%, again mainly cigarette). Only about $20 \%$ of students reported having been taught in school about the dangers of tobacco use, except in Mizoram (around 50\%).(19) In the present study, we tried to create awareness among participants through interviews that had been so designed in the interview schedule. We exchanged our views with the respondents regarding different harmful aspects of smoking or chewing tobacco. In the present study, $17.6 \%$ of respondents started smoking at the age of 20 to 30 years of age. In Tripura, current use of tobacco (any product) was reported by $44.4 \%$ (boys $50.4 \%$, girls $36.9 \%$ ). Current smokeless tobacco use was reported by $35.1 \%$ (boys $39.7 \%$, girls $29.4 \%$ ), whereas smoking by $21.2 \%$ (boys $28.6 \%$, girls $12.4 \%)$.

Cigarette smoking was reported by $10.3 \%$ (boys $13.4 \%$, girls $6.6 \%$ ). Smokeless tobacco use in the form of chewing was reported by $57.5 \%$ and applying by $28.8 \%$.(19) In the present study, we found that $30 \%$ used tobacco in smoking form, $66 \%$ used it in smokeless form and remaining 6\% used both forms of tobacco. A North-East study (2003)(19) reported that never tobacco users felt that tobacco habit was difficult to quit 2 to 4 times more than tobacco users. Among cigarette smokers $32.9 \%$ wanted to quit smoking, far more girls than boys, while $10.7 \%$ students had already tried to stop smoking during the past year. In our study it was found that $88 \%$ of the tobacco users want to quit, but $11 \%$ said difficult to quit due to habit formation. Never users favoured banning smoking in public places 2 - 7 times more often than tobacco users. (19) In present study, $84.7 \%$ were in favour of banning tobacco use in any form. A study conducted in Italy in 2005 showed that $10 \%$ Italian population was found to be overweight, while $22 \%$ said they smoke, $23 \%$ female smokers claiming to be underweight, while for former smokers was minimal. The OR showed that weight gain among former smokers and smokers was actually due to custom/ cessation from tobacco smoke. It was concluded that who quit smoking reflect in gaining weight.(20) A study from Delhi showed that BMI values were higher among nonsmokers compared to smokers who had higher proportion of underweight.(21) A study from Thailand also reported that 
smoking is associated with lower weights and BMI.(22) In present study, lower BMI was found among smokers compared to tobacco users other than smoking $(\mathrm{p}=0.007)$ (Table 3).

\section{CONCLUSION}

Smokeless form of tobacco use was quite high in spite of having good knowledge and awareness. Smoking and chewing forms of tobacco were more frequently used by male and female respectively. There was a significant association between smoking and low BMI.

\section{Strength and Limitation}

We entrusted one individual for height and weight recording throughout the study period to control for interobserver variation. We cannot generalise the present study due to small sample size and limited only to an urban area.

\section{Recommendation}

We recommend further study involving more subjects including rural and urban population.

\section{ACKNOWLEDGEMENT}

We are thankful to all participants without whom this would not have been possible.

\section{REFERENCES}

[1] Rani M, Bonu S, Jha $\mathrm{P}$, et al. Tobacco use in India: prevalence and predictors of smoking and chewing in national cross sectional household survey. Tob Control 2003;12(4):e4.

[2] National sample survey organization (NSSO) 1997. Fifty second National sample survey of household expenditure. New Delhi. Ministry of statistics and programme implementation, Government of India, 1997.

[3] Srivastava A, Pal H, Dwivedi SN, et al. National Household Survey of Drug and Alcohol Abuse in India (NHSDAA). New Delhi. Ministry of Social Justice and Empowerment, Government of India and UN Office for Drug and Crime, Regional Office of South Asia, 2004.

[4] NFHS-IV. Tripura Fact Sheet: NFHS IV, National Institute of Population Science, Deonar, Mumbai, 2015-16: p. 6. htpp//iipsindia.org.

[5] NFHS-IV. India Fact Sheet: NFHS IV, National Institute of Population Science, Deonar, Mumbai, 2015-16: p. 6. htpp//iipsindia.org.

[6] Arora M, Reddy KS. Global Youth Tobacco Survey (GYTS) - Delhi. Indian Peditr 2005;42(8):850-1.

[7] World Health Organization. WHO report on the global tobacco epidemic. The MPOWER Package. Geneva. World Health Organization, 2008.

[8] Jha P, Jacob B, Gajalakshmi V, et al. Report on tobacco control in India. A nationally representative case control study of smoking and death in India. New Engl J of Med 2008;358(11):1137-47.
[9] Cigarette and other tobacco product Act 2003. (amended in 2008). http://www.mohfw.nic.in/WriteReadData/1892s/file 11-82626267.pdf, 19/05/2017.

[10] Sigh A, Ladusingh L. Prevalence and determinants of tobacco use in India: evidence from recent Global Adult Tobacco Survey data. PLoS One 2014;9(12):e114073.

[11] World Health Organization. Physical status: The use and interpretation of Anthropometry. Report of WHO expert committee. Geneva: WHO, 1995.

[12] Molarious A, Seidall JC, Kuulasmaa K, et al. Smoking and relative weight: an International perspective from WHO MONICA project. J Epidemiol Community Health 1997;51(3):252-60.

[13] Marti B, Tuomilehto J, Korhonen HJ, et al. Smoking and leanness: evidence for change in Finland. BMJ 1989;298(6683):1287-90.

[14] Molarious A, Seidall JC. Difference in the association between smoking and relative body weight by level of education. Int $\mathrm{J}$ of Obes Relat Metab Disord 1997;21(3):189-96.

[15] Laaksonen M, Rahkonen O, Prettala O. Smoking status and relative weight by educational level in Finland 1978-95. Preventive Medicine 1998;27(3):431-7.

[16] Pednekar MS, Gupta PC, Shukla HC, et al. Association between tobacco use and body mass index in urban Indian population: implications for public health in India. BMC Public Health 2006;6: p. 70.

[17] Williamson DF, Madans J, Anda RF, et al. Smoking cessation and severity of weight gain in a national cohort. New Engl J Med 1991;324(11):739-45.

[18] Flegal KM, Troiano RP, Pamuk ER, et al. The influence of smoking cessation on the prevalence of overweight in the United States. New Engl J Med 1995;333(18):1165-70.

[19] Sinha DN, Gupta PC, Pednekar MS. Tobacco use among students in the eight North-eastern states of India. Indian J Cancer 2003;40(2):43-59.

[20] De Candia G. Relationship between cigarette smoking and body mass index in the Italian population. Innovare Journal of Health Science 2015;3(1):1-4. https//www.research gate.net.

[21] Chhabra P, Chhabra SK. Effect of smoking and body mass index: a community based study. National Journal of Community Medicine 2011;2(3):325-30.

[22] Jitnarin N, Kosulwat V, Rijroongwasinkul N, et al. The relationship of smoking, body weight, body mass index and dietary intake among Thai adults: results of the National Thai Food Consumption Survey. Asia Pac J Public Health 2014;26(5):481-93. http://journals.sagepub.com/doi/pdf/10.1177/1010 539511426473. 